\title{
Uma história da formação de professores/as no Brasil: Um estudo bibliográfico
}

\author{
A history about teachers' formation in Brazil: A bibliographical study \\ Un estudio acerca de la formación del profesorado en Brasil: Un estudio bibliográfico
}

Recebido: 31/03/2021 | Revisado: 09/04/2021 | Aceito: 13/04/2021 | Publicado: 24/04/2021

\author{
Gabriella Eldereti Machado \\ ORCID: https://orcid.org/0000-0001-5908-4753 \\ Universidade Federal de Santa Maria, Brasil \\ E-mail: gabriellaeldereti@gmail.com \\ Bruna Viedo Kich \\ ORCID: https://orcid.org/0000-0002-7443-7200 \\ Universidade Federal de Santa Maria, Brasil \\ E-mail: Brunavkich@gmail.com \\ Sabrina Copetti da Costa \\ ORCID: https://orcid.org/0000-0002-1057-4425 \\ Universidade Federal de Santa Maria, Brasil \\ E-mail: sabrinacopetti@yahoo.com.br \\ Ivanio Folmer \\ ORCID: https://orcid.org/0000-0002-7433-6434 \\ Universidade Federal de Santa Maria, Brasil \\ E-mail: ivaniofolmer@yahoo.com.br \\ Liziany Müller Medeiros \\ ORCID: https://orcid.org/0000-0001-7325-6611 \\ Universidade Federal de Santa Maria, Brasil \\ E-mail: lizianym@cead.ufsm.br \\ Juliane Paprosqui \\ ORCID: https://orcid.org/0000-0002-3034-2453 \\ Universidade Federal de Santa Maria, Brasil \\ E-mail: juliane_paprosqui@ @otmail.com
}

\begin{abstract}
Resumo
Após a independência brasileira, surgem no país os primeiros contextos de formação de professores/as. O tema, ainda amplamente discutido, sofre alterações a cada modificação ou implementação das políticas públicas vigentes. Dessa forma, esse artigo objetiva brevemente discorrer sobre a historicidade do processo formativo de professore/as no cenário brasileiro, de 1827 até aos dias atuais. Propõem-se então, através de uma pesquisa bibliográfica nos trabalhos publicados pelos autores mais proeminentes na área e de documentos que regem a legislação brasileira, discutir os seis períodos apontados por Demerval Saviani e pelo contexto atual acerca da formação de professores/as presentes na Base Nacional Comum Curricular (BRASIL, 2019). Contatou-se uma nova visão acerca da formação docente, a qual prioriza o contexto prático da profissão, em detrimento do teórico. Verificou-se também a ausência de diálogo nas políticas públicas implementadas, onde pesquisadores da área da formação foram pouco ou não foram ouvidos, causando hiatos e estilhaços na formação de professores.
\end{abstract}

Palavras-chave: Ensino; Formação de professores/as; Políticas públicas; BNCC.

\begin{abstract}
After Brazilian Independence, the first contexts about teachers' formation appear in the country. The theme, still widely discussed, suffer alterations on each modification or implementation of public policies. Thus, this article aims to briefly point out the historicity of the formative processes of teachers in the Brazilian context from 1827 to the current days. By performing a bibliographical result on the most prominent authors in the field and the documents that rule the Brazilian legislation, to discuss the six periods pointed out by Demerval Saviani and by the current context about the teachers' formation presented on the National Common Curricular Base (BRASIL, 2019). It was verified a new vision about teachers' formation, which prioritizes the practical context of the profession instead of the theoretical one. It was also verified the lack of dialogue in the public policies, where researchers in the area of formation were a little or no listened, causing gaps and shards on teachers' formation.
\end{abstract}

Key-words: Teaching; Teacher's formation; Public policies; BNCC.

\section{Resumen}

Después de la independencia brasileña, aparecieron los primeros contextos de formación docente en el país. El tema, aun ampliamente discutido, sufre cambios con cada modificación o implementación de las políticas públicas vigentes. Así, este estudio tiene como objetivo discutir brevemente la historicidad del proceso de formación docente en el 
escenario brasileño, desde 1827 hasta la actualidad. Mediante una búsqueda bibliográfica en los trabajos publicados por los autores más destacados del área y el de los documentos que rigen la legislación brasileña, se propone a discutir los seis períodos señalados por Demerval Saviani y el contexto actual sobre la formación de docentes presentes en la Base Curricular Nacional Común (BRASIL, 2019). Se contactó con una nueva visión sobre la formación del profesorado, que prioriza el contexto práctico de la profesión, en detrimento del teórico. También hubo una ausencia de diálogo en las políticas públicas implementadas, donde los investigadores en el campo de la formación fueron poco o no escuchados, provocando vacíos y escisiones en la formación de los docentes.

Palabras clave: Ensenãnza; Formación del profesorado; Políticas públicas; BNCC.

\section{Introdução}

A formação de professores/as no Brasil traz ao contexto da educação diversos debates, sendo um deles a constituição dos modelos de formação, desse modo torna-se relevante a compreensão da perspectiva histórica dos processos que constituíram essa área. Assim, transcorre-se sobre períodos históricos que constituíram a formação de professores/as no Brasil.

Levando-se em conta que a docência e a formação vão muito além da articulação dos conteúdos, de acordo com Pimenta (2012, p.32), “a formação é, na verdade, auto formação, uma vez que os professores reelaboram os saberes iniciais em confronto com suas experiências práticas", fortificando a ideia de que a compreensão e a formação docente sejam um processo contínuo, tendo seu início durante a formação inicial do/a professor/a.

Ficando evidente que o processo de constituição docente é composto de diversas etapas, que contemplam uma complexidade para além dos conteúdos, levando - se em conta olhares, caminhos e significados atribuídos por cada discente no contexto escolar que se insere, desta forma destaca - se o seguinte trecho de Brancher, et. al. (2007, p. 65) que complementa o que foi disposto anteriormente:

Não esquecendo de que cada trajetória, indiferente aos momentos/lócus vividos pelos sujeitos, é única e intransferível. Assim, os indivíduos, neste caso os professores, ao perpassarem por inúmeros momentos formativos, positiva ou negativamente, vão se construindo. E cada momento situacional por eles vividos - crises, nascimentos, casamentos, despedidas, paixões, eventos - consiste num processo formativo.

Sendo assim, é relevante neste momento formativo que o sujeito em formação possua a sua leitura sobre a docência, através da posse de seu material existencial e da construção de referenciais de formação (OLIVEIRA, 2000). Neste sentido, as aprendizagens durante a formação inicial são ligadas à sua contextualização na prática docente, pois como menciona Cunha (2005, p. 90), “os saberes de início de carreira se constroem através da prática, tateando e descobrindo”. Sendo complementado pela ideia de Brancher (2006, p.73), onde ressalta:

Olhar os processos formativos é uma nova forma de perceber as lacunas instauradas na formação universitária e em outros processos formativos, formação essa que, embora construída individual e diariamente pelos sujeitos, também pode ser trabalhada, intensificada e construída na escola e na coletividade, sendo necessário, para tanto, entender as instituições enquanto espaços coletivos de formação.

Em ressalva ao cenário mundial, a formação de professores/as surge como uma necessidade a partir do chamado Seminário dos Mestres, no século XVII, por meio de Comenius, que era um bispo protestante e pedagogo percursor da didática (Batista, 2017). Era no Seminário dos Mestres o local onde ocorria a formação de professores/as, passando posteriormente no período da Revolução Francesa a promoção da valorização da instrução escolar, com o surgimento das Escolas Normais.

A pesquisa sobre a formação docente, aproximam-se das reflexões sobre o saber em momentos históricos, podendo ser compreendido como um poder simbólico, pois as desigualdades sociais realizam-se por meio de condicionamentos materiais, relações econômicas, e simbólicas, relações culturais como escolarização e status social (Bourdieu, 1989).

No Brasil, a formação de professores/as surge no período pós independência, com a organização dos processos de 
instrução popular, como eram chamados (Borges, Aquino \& Puentes, 2011). Conforme aponta Saviani (2009), a formação no Brasil é dividida em seis períodos históricos, sendo eles: Ensaios intermitentes de formação de professores (1827-1890); Estabelecimento e expansão do padrão das Escolas Normais (1890-1932); Organização dos Institutos de Educação (19321939); Organização e implantação dos Cursos de Pedagogia e de Licenciatura e consolidação do modelo das Escolas Normais (1939-1971); Habilitação Específica de Magistério (1971-1996); Institutos Superiores de Educação, Escolas Normais Superiores (1996-2006).

O objetivo desta escrita é contextualizar a formação de professores/as por meio de aspectos históricos do cenário brasileiro, discutindo sobre os seis períodos apontados por Saviani, e trazendo o contexto atual da BNCC da formação de professores/as (2019). Como metodologia, adota-se a pesquisa bibliográfica em fontes como artigos científicos e legislação educacional.

\section{Metodologia}

Toda pesquisa possui um propósito, no qual se espera aventurar-se pelos conhecimentos e aprendizagem que irão possibilitar a compreensão da realidade pesquisada, em um sentido amplo, como reflete Pádua (2004, p.31) é a "atividade de busca, indagação, investigação, inquirição da realidade, é a atividade que vai nos permitir, (...)”. Desta forma, a pesquisa é um processo de olhares, no qual a originalidade encontra-se na criação, se distanciando da mera constatação. Em meio à troca de experiências e partilha de saberes consolidando um processo formativo mútuo, onde através da pesquisa se consolida redes coletivas de trabalho, com o propósito de socialização profissional (Nóvoa, 1995).

O presente trabalho tem como caminho metodológico a pesquisa qualitativa, por meio do uso do método documental. Concordando com o que menciona Pereira (2018, p.28) "O método científico é um trabalho sistemático, na busca de respostas às questões estudadas, é o caminho que se deve seguir para levar à formulação de uma teoria científica. É um trabalho cuidadoso, que segue um caminho sistemático".

Indo de encontro a ideia sobre pesquisa trazida por Deslandes, onde ressalta que (1994, p.16) "Entendemos por metodologia o caminho do pensamento e a prática exercida na abordagem da realidade". No qual a teoria e informações contidas em fontes de pesquisa, no caso desse trabalho em documentos sobre a formação docente, ajudam na compreensão de um fenômeno ou processo sobre o campo analisado. Sendo assim, como diz Deslandes (1994, p.21) "A pesquisa qualitativa responde a questões muito particulares".

Desse modo, é utilizado para construção desse estudo a pesquisa documental, no qual é priorizado segundo Sá-Silva, et. al. (2009, p.02):

$\mathrm{O}$ uso de documentos em pesquisa deve ser apreciado e valorizado. A riqueza de informações que deles podemos extrair e resgatar justifica o seu uso em várias áreas das Ciências Humanas e Sociais porque possibilita ampliar o entendimento de objetos cuja compreensão necessita de contextualização histórica e sociocultural.

Possibilitando aos pesquisadores adentrar a uma compreensão social e histórica por meio dos documentos acessados. A pesquisa documental possui semelhanças com a bibliográfica, como ressalta-se abaixo:

Tanto a pesquisa documental como a pesquisa bibliográfica têm o documento como objeto de investigação. No entanto, o conceito de documento ultrapassa a idéia de textos escritos e/ou impressos. O documento como fonte de pesquisa pode ser escrito e não escrito, tais como filmes, vídeos, slides, fotografias ou pôsteres. (Sá-Silva, et. al., 2009, p.0)

Devido a estas possibilidades oferecidas pela pesquisa documental, utiliza-se a mesma na busca dos trajetos 
formativos de docentes em documentos que contam sobre esses processos, podendo desse modo ter uma visão ampla da história da formação de professores/as no Brasil.

\section{Lei das Escolas de Primeiras Letras (1824)}

A Lei das Escolas de Primeiras Letras, promulgada no ano de 1824 por Dom Pedro I no período do Brasil Império. Nela, eram garantidas de forma gratuita a instrução a todos/as cidadãos, posteriormente a isto, no ano de 1827, é apresentado o projeto de lei criando as escolas primárias em diferentes localidades do Brasil. A seguir, procedemos com a apresentação da Lei das Escolas de Primeiras Letras (1824) conforme descrição do documento da mesma.

A Lei tinha como base a implementação de Escolas de Primeiras Letras em cidades mais populosas, no qual as escolas eram estruturadas por meio do ensino mútuo nas capitais das províncias (Brasil Império, 1827). Nessas escolas era prevista também a "instrução" ou como chamamos, a formação dos/as professores/as, conforme Artigo $5^{\circ}$ :

Art. $5^{\circ}$ Para as escolas do ensino mútuo se aplicarão os edifícios, que couberem com a suficiência nos lugares delas, arranjando-se com os utensílios necessários à custa da Fazenda Pública e os Professores que não tiverem a necessária instrução deste ensino, irão instruir-se em curto prazo e à custa dos seus ordenados nas escolas das capitais. (Brasil Império, 1827 , p. S/N)

Era tarefa dos/as professores/as nas Escolas de Primeiras Letras as funções básicas de ensino de leitura, escrita e de matemática, com o enfoque cristão e de princípios morais católicos no ensino. Como é mencionado no Artigo $6^{\circ}$ :

Art. $6^{\circ}$ Os professores ensinarão a ler, escrever, as quatro operações de aritmética, prática de quebrados, decimais e proporções, as noções mais gerais de geometria prática, a gramática de língua nacional, e os princípios de moral cristã e da doutrina da religião católica e apostólica romana, proporcionados à compreensão dos meninos; preferindo para as leituras a Constituição do Império e a História do Brasil. (Brasil Império, 1827, p. S/N)

Nesse contexto, os cargos de docentes eram vitalícios, podendo ainda assim serem suspensos e/ou demitidos caso fosse de escolha dos presidentes que fiscalizavam as escolas. Os procedimentos pedagógicos adotados pelos/as professores/as nessa época tinham como base o ensino mútuo. Esse método era a base da formação docente nesse período, sendo consequentemente a base do ensino nas Escolas de Primeiras Letras.

O ensino mútuo, também chamado de Método Lancaster, tem como agente do ensino o/a professor/a, consistia na divisão dos/as alunos/as em diferentes classes, de acordo com o nível de conhecimento que tinham. E os/as professores/as representavam a figura de instrutores, pois tinham um conhecimento maior a partir dessa concepção de ensino (Marchelli, 2017). Como descreve-se abaixo:

O método lancasteriano, também chamado sistema monitorial foi criado por Andrew Bell e Joseph Lancaster na Inglaterra do final do Século XVIII e início do XIX, que passava por um processo acelerado de industrialização e produziu uma ampla concentração populacional urbana. Segundo Castanha (2012), o objetivo político do método era baratear a instrução das classes mais pobres por meio da optimização do trabalho do professor, de forma que este pudesse ensinar a uma grande quantidade de alunos ao mesmo tempo em que mantinha controle sobre o progresso dos mesmos. O professor ensinava a matéria primeiramente para um conjunto de alunos selecionados entre os mais aptos e organizava os demais em pequenos grupos, que eram instruídos pelos que já tinham aprendido. O sistema era controlado por uma disciplina rigorosa, em que cada aluno tinha um lugar definido pelo seu nível de conhecimento e mudava de posição em relação aos demais à medida que progredia nas lições. O método foi difundido para além das fronteiras inglesas e levado à França, Portugal, Suíça, regiões que constituiriam futuramente a Alemanha, Itália, Estados Unidos, Brasil e ainda outros países. (Marchelli, 2017, p.226)

No período descrito, não havia propriamente dita programas ou espaços de formação docente, a educação no contexto 
imperial estava traçando passos iniciais, que culminam na implementação das Escolas Normais de formação, sendo essas voltadas a formar professores/as.

\section{Escolas Normais de Formação (1879)}

A implementação das Escolas Normais de formação surge da necessidade de organizar os processos de instrução primária e secundária no Brasil. Como também, da vontade do Imperador de concretizar a instituição de estatutos para a fundação de Faculdades de Direito, Medicina e as Escola Politécnicas. Conforme decreto que instituía as Escolas Normais, temos:

Art. $1^{10} E^{\prime}$ completamente livre o ensino primario e secundario no municipio da Côrte e o superior em todo o Imperio, salvo a inspecção necessaria para garantir as condições de moralidade e hygiene. (Brasil Império, 1879, p. S/N)

Com as Escolas Normais, a formação de professores/as torna-se abrangente, no sentido de que contemplava uma série de conhecimentos diversos, a fim de que esses profissionais dessem conta posteriormente do ensino em níveis primários e secundários. Assim, conforme o Artigo $9^{\circ}$, propunha-se a formação docente por meio da aprendizagem dos seguintes temas:

Art. $9^{\circ 2} \mathrm{O}$ ensino nas Escolas Normaes do Estado comprehenderá as disciplinas mencionadas nos dous primeiros paragraphos seguintes:

$\S 1^{\circ}$ Lingua nacional. Lingua franceza. Arithmetica, algebra e geometria. Metrologia e escripturação mercantil. Geographia e cosmographia. Historia universal. Historia e geographia do Brazil. Elementos de sciencias physicas e naturaes, e de physiologia e hygiene. Philosophia. Principios de direito natural e de direito publico, com explicação da Constituição politica do Imperio. Principios de economia politica. Noções de economia domestica (para as alumnas). Pedagogia e pratica do ensino primario em geral. Pratica do ensino intuitivo ou lições de cousas. Principios de lavoura e horticultura. Calligraphia e desenho linear. Musica vocal. Gymnastica. Pratica manual de officios (para os alumnos). Trabalhos de agulha (para as alumnas). Instrucção religiosa (não obrigatoria para os acatholicos).

$\S 2^{\circ}$ Latim. Inglez. Allemão. Italiano. Rhetorica. (Brasil Império, 1879, p. S/N)

A partir das Escolas Normais, e de sua instituição por meio de um decreto, o ensino nas escolas primárias tomam como foco a instrução moral, religiosa, leitura, escrita, noções de gramática e aritmética, sistema de pesos e medidas, história e geografia, música, ginástica, e costura simples para no caso das escolas de meninas. Já o ensino nas escolas de segundo grau, possuía as disciplinas mencionadas anteriormente, com a adição de: álgebra e geometria, física, química, história natural, organização política do Império, lavoura e horticultura, economia, e economia doméstica voltada a educação das meninas.

\section{A Organização dos Institutos de Educação (1932-1939) a Partir das Reformas de Anísio Teixeira}

No período posterior ao das Escolas Normais, já na década de 1930, no governo de Getúlio Vargas, tem-se a organização da formação de docentes por meio da criação dos Institutos de Educação, com base nas reformas de Anísio Teixeira, sendo o principal percursor dessas mudanças.

Anísio Teixeira, foi um jurista, educador e escritor brasileiro, nascido na Bahia, participou ativamente dos debates voltados a universalização do ensino público, gratuito e obrigatório. Defendendo a educação no viés do construtivismo, com base na Educação Nova, no qual sua premissa estava no papel dos/as alunos/as como agentes transformadores da sociedade (Borges, Aquino \& Puentes, 2011).

\footnotetext{
${ }^{1}$ Mantêm-se a grafia original do documento.

${ }^{2}$ Mantêm-se a grafia original do documento.
} 
Desse modo, os Institutos de Educação surgem como uma nova fase na formação dos/as professores/as, sendo concebido inicialmente no Distrito Federal, implantado em 1932, e posteriormente em São Paulo, em 1933, nesse caso implantado por Fernando de Azevedo (Saviani, 2009). Tendo como marco de implantação o Decreto 3.810, de 19 de março de 1932, com o principal objetivo de reorganização da proposta das Escolas Normais.

Sendo ampliado no projeto aspectos relacionados a formação cultural e profissional, incorporando a pedagogia no sentido de formação para um conhecimento de caráter científico. E a partir disto, consolidar um modelo pedagógico e didático para a formação docente (Saviani, 2009). Com a preocupação de criar universidades para a formação dos profissionais docentes, pois até o momento, essa atividade de ensino era realizada por pessoas autodidatas ou que tinham notório saber em alguma área.

Os movimentos da década de 1930 relacionados a educação no Brasil tinham como principal incentivo o cenário de industrialização que o país estava passando, que trouxe a necessidade de que a população tivesse uma maior escolaridade. Desse modo, temos:

Ao avançar na história, chega-se ao quarto período, o qual se caracterizou pela "Organização e implantação dos cursos de Pedagogia e de Licenciatura e consolidação no padrão das Escolas Normais (1939-1971)”. Os Institutos de Educação do Distrito Federal e de São Paulo foram elevados ao nível universitário, tornando-se a base dos estudos superiores de educação: o paulista incorporado à Universidade de São Paulo fundada em 1934, e o carioca à Universidade do Distrito Federal, criada em 1935. (Borges, Aquino \& Puentes, 2011, p.99)

No qual, a partir do Decreto de Lei no 1.190 de 1939, é instituída a Faculdade Nacional de Filosofia, como sendo um curso a nível universitário de formação docente, com as seguintes finalidades:

Art. $1^{\circ}$ A Faculdade Nacional de Filosofia, Ciências e Letras, instituida pela Lei n. 452, de 5 de julho de 1937, passa a denominar-se Faculdade Nacional de Filosofia. Serão as seguintes as suas finalidades:

a) preparar trabalhadores intelectuais para o exercício das altas atividades de ordem desinteressada ou técnica;

b) preparar candidatos ao magistério do ensino secundário e normal;

c) realizar pesquisas nos vários domínios da cultura, que constituam objeto de ensino. (Brasil, 1939, p. S/N)

A Faculdade Nacional de Filosofia compreendia seções fundamentais de conteúdos e áreas do conhecimento voltadas a formação docente, sendo elas: filosofia; ciências; letras; e pedagogia. Além de uma seção especial voltada a questões de aprendizagem e didática. Sendo este um marco histórico para a formação docente, pois até então não havia cursos ou faculdades que contemplassem a profissionalização intelectual dos/as docentes.

\section{As Escolas Normais de Formação (1939-1971)}

Em sequência ao período descrito anteriormente, temos a criação das Escolas Normais de formação, no período posterior a 1939 (Saviani, 2009). No qual, cria-se o curso de Pedagogia, cercado de discussões relacionadas ao modelo de formação, onde insere-se o modelo dos conteúdos culturais-cognitivos na formação docente.

Onde a partir do Decreto-lei No 8.530 de 1946, traça a organização da ideia das Escolas Normais de formação docente. Prevendo como finalidades do Ensino Normal como:

Art. $1^{\circ} \mathrm{O}$ ensino normal, ramo de ensino do segundo grau, tem as seguintes finalidades: 1. Prover à formação do pessoal docente necessário às escolas primárias. 2. Habilitar administradores escolares destinados às mesmas escolas. 3. Desenvolver e propagar os conhecimentos e técnicas relativas à educação da infância. (Brasil, 1946, p. S/N) 
O Ensino Normal era organizado em dois ciclos, no qual o primeiro era respectivo ao nível primário, com duração de quatro anos, e o segundo nível voltado a formação de professores/as primários/as, com duração de três anos. Havia a possibilidade de habilitação para o ensino primário e para a administração escolar. Sendo descritas as estruturas das modalidades a seguir:

Art. $7^{\circ} \mathrm{O}$ curso de regentes de ensino primário se fará em quatro séries anuais, compreendendo, no mínimo, as seguintes disciplinas:

Primeira série: 1) Português. 2) Matemática. 3) Geografia geral. 4) Ciências naturais. 5) Desenho e caligrafia. 6) Canto orfeônico. 7) Trabalhos manuais e economia doméstica. 8\} Educação física.

Segunda série: 1) Português. 2) Matemática. 3) Geografia do Brasil. 4) Ciências naturais. 5) Desenho e caligrafia. 6) Canto orfeônico. 7) Trabalhos manuais e atividades econômicas da região. 8) Educação física.

Terceira série: 1) Português. 2) Matemática. 3) História geral. 4) Noções de anatomia e fisiologia humanas. 5) Desenho. 6) Canto orfeônico. 7) Trabalhos manuais e atividades econômicas da região. 8) Educação física, recreação e jogos.

Quarta série: 1) Português. 2) História do Brasil. 3) Noções de Higiene. 4) Psicologia e pedagogia. 5. Didática e prática de ensino. 6) Desenho. 7) Canto orfeônico. 8) Educação física, recreação e jogos. (Brasil, 1946, p. S/N)

Com relação ao curso de formação de professores/as primários/as, formulado no período de três séries anuais, disponha das seguintes disciplinas:

Art. $8^{\circ} \mathrm{O}$ curso de formação de professores primários se fará em três séries anuais, compreendendo, pelo menos, as seguintes disciplinas:

Primeira série : 1) Português. 2) Matemática. 3) Física e química. 4) Anatomia e fisiologia humanas. 5) Música e canto. 6) Desenho e artes aplicadas. 7) Educação física, recreação, e jogos.

Segunda série: 1) Biologia educacional. 2) Psicologia educacional. 3) Higiene e educação sanitária. 4) Metodologia do ensino primário. 5) Desenho e artes aplicadas. 6) Música e canto. 7) Educação física, recreação e jogos.

Terceira série: 1) Psicologia educacional. 2) Sociologia educacional. 3) História e filosofia da educação. 4) Higiene e puericultura. 5) Metodologia do ensino primário. 6) Desenho e artes aplicadas. 7) Música e canto, 8) Prática do ensino. 9) Educação física, recreação e jogos. (Brasil, 1946, p. S/N)

Com relação a formação em administração escolar, possibilitada pela proposta das Escolas Normais, tinham como organização:

Art. 10. Os cursos de especialização de ensino normal compreenderão os seguintes ramos: educação pré-primária; didática especial do curso complementar primário; didática especial do ensino supletivo; didática especial de desenho e artes aplicadas; didática especial de música e canto.

Art. 11. Os cursos de administradores escolares do grau primário visarão habilitar diretores de escolas, orientadores de ensino, inspetores escolares, auxiliares estatísticos e encarregados de provas e medidas escolares. (Brasil, 1946, p. $\mathrm{S} / \mathrm{N})$

Pode-se perceber neste período alguns avanços significativos quanto a organização dos cursos de formação de professores/as, que posteriormente no período da década de 1970 a 1990 torna-se o chamado Magistério.

\section{Formação Através da Habilitação Específica de Magistério (1971-1996)}

Após o Golpe Militar de 1964, ocorrem modificações no sistema educacional no Brasil e consequentemente nos programas de formação docente, sendo mudanças no campo da legislação do ensino. Como a alteração das denominações de ensino primário e médio para primeiro grau e segundo grau (Saviani, 2009).

E com isso, a estrutura das Escolas Normais acabam desaparecendo, sendo colocadas no lugar a habilitação específica de $2^{\circ}$ grau para o exercício do magistério de $1^{\circ}$ grau (Saviani, 2009). A habilitação do magistério era composta por duas modalidades, sendo a primeira de duração de três anos habilitando para docentes para o ensino até a $4^{\mathrm{a}}$ série. E a segunda, com 
duração de quatro anos, habilitando para o ensino da $6^{\mathrm{a}}$ série ao $1^{\circ}$ grau, termos utilizados no documento. Porém, esse modelo de formação docente tinha muitos problemas, sendo destacados por Saviani:

A evidência e gravidade dos problemas levaram o governo a lançar, em 1982, o projeto Centros de Formação e Aperfeiçoamento do Magistério (CEFAMs), que teve o caráter de "revitalização da Escola Normal" (Cavalcante, 1994, p. 59, 76 e 123). Mas esse projeto, apesar dos resultados positivos, foi descontinuado quando seu alcance quantitativo era ainda restrito, não tendo havido também qualquer política para o aproveitamento dos professores formados pelos centros nas redes escolares públicas. (Saviani, 2009, p.147)

Uma mudança relacionada ao ensino em nível de $2^{\circ}$ grau, foi a exigência de formação em nível superior dos/as professores/as, sendo em cursos de licenciatura curta que tinham duração de três anos, ou plena, com duração de quatro anos. E em relação a formação em Pedagogia, tinha-se as seguintes possibilidades:

Ao curso de Pedagogia, além da formação de professores para habilitação específica de Magistério (HEM), conferiuse a atribuição de formar os especialistas em Educação, aí compreendidos os diretores de escola, orientadores educacionais, supervisores escolares e inspetores de ensino. (Saviani, 2009, p.147)

Nesse contexto apresentado da década de 1970 a 1990 consegue-se perceber avanços relacionados a exigência de formação superior a nível de curso de licenciatura para atuação no ensino, porém, a estruturação da habilitação do magistério ainda possuía déficits formativos, sendo na proposta posterior a 1996 com os Institutos Superiores de Educação como uma alternativa de modificação e formação.

\section{Institutos Superiores de Educação e a Formação Docente (1996-2006)}

Com o cenário de redemocratização no Brasil, tem-se uma série de mobilizações de setores da sociedade buscando melhorias e processos igualitários a todos/as. Em relação a formação docente não foi diferente, ocorre no período da década de 1990 discussões acerca de melhorias e modificações na Lei de Diretrizes e Bases da educação (LDB). Sendo um novo documento promulgado no ano de 1996.

A LDB de 1996 traz como proposta a formação docente em cursos de pedagogia e licenciaturas a criação de Institutos Superiores de Educação, como uma política voltada a formação a nível superior dos/as professores/as (Saviani, 2009). Em uma primeira proposta, surgem os Institutos como uma forma de promoção da formação docente em cursos de curta duração.

Por meio da LDB de 1996, é promulgado sobre os/as profissionais da educação e sua formação devem ter como base o Artigo 61:

Art. 61. A formação de profissionais da educação, de modo a atender aos objetivos dos diferentes níveis e modalidades de ensino e às características de cada fase do desenvolvimento do educando.

Art. 61. Consideram-se profissionais da educação escolar básica os que, nela estando em efetivo exercício e tendo sido formados em cursos reconhecidos, são: (Redação dada pela Lei $n^{\circ} 12.014$, de 2009)

I - a associação entre teorias e práticas, inclusive mediante a capacitação em serviço;

I - professores habilitados em nível médio ou superior para a docência na educação infantil e nos ensinos fundamental e médio; $\quad$ (Redação dada pela Lei $n^{\circ}$ 12.014, de 2009)

II - aproveitamento da formação e experiências anteriores em instituições de ensino e outras atividades.

II - trabalhadores em educação portadores de diploma de pedagogia, com habilitação em administração, planejamento, supervisão, inspeção e orientação educacional, bem como com títulos de mestrado ou doutorado nas mesmas áreas; $\quad$ (Redação dada pela Lei n ${ }^{\circ} 12.014$, de 2009)

III - trabalhadores em educação, portadores de diploma de curso técnico ou superior em área pedagógica ou afim. (Incluído pela Lei $\mathrm{n}^{\circ} 12.014$, de 2009)

III - trabalhadores em educação, portadores de diploma de curso técnico ou superior em área pedagógica ou afim; e (Redação dada pela Medida Provisória n ${ }^{\circ} 746$, de 2016)

III - trabalhadores em educação, portadores de diploma de curso técnico ou superior em área pedagógica ou afim. (Incluído pela Lei n 12.014, de 2009) 
IV - profissionais com notório saber reconhecido pelos respectivos sistemas de ensino para ministrar conteúdos de áreas afins à sua formação para atender o disposto no inciso V do caput do art. 36. (Incluído pela Medida Provisória $\mathrm{n}^{\mathrm{o}} 746$, de 2016)

IV - profissionais com notório saber reconhecido pelos respectivos sistemas de ensino, para ministrar conteúdos de áreas afins à sua formação ou experiência profissional, atestados por titulação específica ou prática de ensino em unidades educacionais da rede pública ou privada ou das corporações privadas em que tenham atuado, exclusivamente para atender ao inciso V do caput do art. 36; (Incluído pela lei no 13.415, de 2017)

$\mathrm{V}$ - profissionais graduados que tenham feito complementação pedagógica, conforme disposto pelo Conselho Nacional de Educação. (Incluído pela lei no 13.415, de 2017). (Brasil, 1996, p. S/N)

No qual, propõe-se que a formação docente tem como fundamentos a formação básica com conhecimentos científicos e sociais voltados as competências de trabalho. Através da relação entre a teoria e a prática sendo realizadas nos estágios supervisionados, e um dos destaques que fica assegurado em Lei é a de que a formação docente para atuação em níveis básicos de ensino deve ser realizada em instituições de nível superior, em cursos de licenciatura. Conforme consta no Artigo 62:

Art. 62. A formação de docentes para atuar na educação básica far-se-á em nível superior, em curso de licenciatura, de graduação plena, em universidades e institutos superiores de educação, admitida, como formação mínima para o exercício do magistério na educação infantil e nas quatro primeiras séries do ensino fundamental, a oferecida em nível médio, na modalidade Normal. Regulamento)

Art. 62. A formação de docentes para atuar na educação básica far-se-á em nível superior, em curso de licenciatura, de graduação plena, em universidades e institutos superiores de educação, admitida, como formação mínima para o exercício do magistério na educação infantil e nos 5 (cinco) primeiros anos do ensino fundamental, a oferecida em nível médio na modalidade normal. (Redação dada pela Lei nº 12.796, de 2013)

Art. 62. A formação de docentes para atuar na educação básica far-se-á em nível superior, em curso de licenciatura plena, admitida, como formação mínima para o exercício do magistério na educação infantil e nos cinco primeiros anos do ensino fundamental, a oferecida em nível médio, na modalidade normal. (Redação dada pela lei $n^{\circ} 13.415$, de 2017). (Brasil, 1996, p. S/N)

Por meio da LDB, também é assegurado questões relacionadas as condições de profissionalização e trabalho docente, como o ingresso por meio de concurso público; aperfeiçoamento profissional; piso salarial; progressão funcional; e condições para o trabalho.

No ano de 2002, frente a políticas democráticas e populares de incentivo a educação e expansão do ensino superior no Brasil, cria-se após uma série de discussões as Diretrizes Curriculares Nacionais para a Formação de Professores da Educação Básica, em nível superior, curso de licenciatura, de graduação plena (2002) como proposta voltada a formação docente.

O documento previa com base em processos democráticos e de acesso a educação a melhoria da qualidade da educação básica, e desse modo, aprova-se o Parecer CNE/CP de 2001, contendo a proposta inicial das Diretrizes de 2002. Propondo mudanças nos processos de formação docente nas instituições de ensino superior, com objetivos voltados a:

(...) fortalecer e aprimorar a capacidade acadêmica e profissional dos docentes formadores; atualizar e aperfeiçoar os formatos de preparação e os currículos vivenciados, considerando as mudanças em curso na organização pedagógica e curricular da educação básica; dar relevo à docência como base da formação, relacionando teoria e prática; promover a atualização de recursos bibliográficos e tecnológicos em todas as instituições ou cursos de formação. (Brasil, 2002, p. S/N)

Em conjunto a proposta de melhoria da formação de docentes para a educação básica, as Diretrizes trouxeram mudanças no meio acadêmico, voltando ao corpo docente formador, com o sistema nacional de desenvolvimento profissional, melhoria da infraestrutura das universidades, processos de avaliação das Instituições de Ensino Superior, planos de carreira dos/as docentes do ensino superior.

Buscando por meio das Diretrizes promover a relação entre a formação docente e os princípios descritos na Lei de Diretrizes e Bases da Educação Nacional/LDBEN. Sendo o currículo das licenciaturas com a seguinte organização: 
Art. $2^{\circ}$ - A organização curricular de cada instituição observará, além do disposto nos artigos 12 e 13 da Lei n 9.394 , de 20 de dezembro de 1996 (LDB), outras formas de orientação inerentes à formação para a atividade docente, entre as quais o preparo para:

I. o ensino visando à aprendizagem do aluno;

II. o acolhimento e o trato da diversidade;

III. o exercício de atividades de enriquecimento cultural;

IV. o aprimoramento em práticas investigativas;

V. a elaboração e a execução de projetos de desenvolvimento dos conteúdos curriculares;

VI. o uso de tecnologias da informação e da comunicação e de metodologias, estratégias e materiais de apoio inovadores;

VII. o desenvolvimento de hábitos de colaboração e de trabalho em equipe. (Brasil, 2002, p. S/N)

Atualmente, já aprovada, tem-se a proposta de novas diretrizes para a formação docente, voltadas a construção de um núcleo nacional comum de conhecimentos e propostas formativas, sendo esta apresentada a seguir.

\section{BNCC da Formação de Professores/as (2019)}

Aprovada em 2019, e promulgada em 2020, as Diretrizes Curriculares Nacionais para a Formação Continuada de Professores da Educação Básica e institui a Base Nacional Comum para a Formação Continuada de Professores da Educação Básica (BNC-Formação Continuada) constituem modificações aos programas e cursos de formação continuada de professores/as no Brasil.

A BNC da formação de professores/as tem como foco o modelo voltado ao desenvolvimento de competências profissionais, conforme Artigo $3^{\circ}$ :

Art. $3^{\circ}$ As competências profissionais indicadas na BNCC-Formação Continuada, considerando que é exigido do professor sólido conhecimento dos saberes constituídos, das metodologias de ensino, dos processos de aprendizagem e da produção cultural local e global, objetivando propiciar o pleno desenvolvimento dos educandos, têm três dimensões que são fundamentais e, de modo interdependente, se integram e se complementam na ação docente no âmbito da Educação Básica:

I - conhecimento profissional;

II - prática profissional; e

III - engajamento profissional. (Brasil, 2020, p. S/N)

Constituindo desse modo, uma base nacional comum, integrando os cursos de licenciatura em prol de uma formação voltada as competências. Sendo o documento alicerçado em 10 competências: 
Quadro 1 - Competências da BNC da formação.

1. Compreender e utilizar os conhecimentos historicamente construídos para poder ensinar a realidade com engajamento na aprendizagem do estudante e na sua própria aprendizagem, colaborando para a construção de uma sociedade livre, justa, democrática e inclusiva.

2. Pesquisar, investigar, refletir, realizar análise crítica, usar a criatividade e buscar soluções tecnológicas para selecionar, organizar e planejar práticas pedagógicas desafiadoras, coerentes e significativas.

3. Valorizar e incentivar as diversas manifestações artísticas e culturais, tanto locais quanto mundiais, e a participação em práticas diversificadas da produção artístico-cultural para que o estudante possa ampliar seu repertório cultural.

4. Utilizar diferentes linguagens - verbal, corporal, visual, sonora e digital - para se expressar e fazer com que o estudante amplie seu modelo de expressão ao partilhar informações, experiências, ideias e sentimentos em diferentes contextos, produzindo sentidos que levem ao entendimento mútuo.

5. Compreender, utilizar e criar tecnologias digitais de informação e comunicação de forma crítica, significativa, reflexiva e ética nas diversas práticas docentes, como recurso pedagógico e como ferramenta de formação, para comunicar, acessar e disseminar informações, produzir conhecimentos, resolver problemas e potencializar as aprendizagens.

6. Valorizar a formação permanente para o exercício profissional, buscar atualização na sua área e afins, apropriar-se de novos conhecimentos e experiências que lhe possibilitem aperfeiçoamento profissional e eficácia e fazer escolhas alinhadas ao exercício da cidadania, ao seu projeto de vida, com liberdade, autonomia, consciência crítica e responsabilidade.

7. Desenvolver argumentos com base em fatos, dados e informações científicas para formular, negociar e defender ideias, pontos de vista e decisões comuns, que respeitem e promovam os direitos humanos, a consciência socioambiental, o consumo responsável em âmbito local, regional e global, com posicionamento ético em relação ao cuidado de si mesmo, dos outros e do planeta.

8. Conhecer-se, apreciar-se e cuidar de sua saúde física e emocional, compreendendo-se na diversidade humana, reconhecendo suas emoções e as dos outros, com autocrítica e capacidade para lidar com estas, desenvolver o autoconhecimento e o autocuidado nos estudantes.

9. Exercitar a empatia, o diálogo, a resolução de conflitos e a cooperação, fazendo-se respeitar e promovendo o respeito ao outro e aos direitos humanos, com acolhimento e valorização da diversidade de indivíduos e de grupos sociais, seus saberes, identidades, culturas e potencialidades, sem preconceitos de qualquer natureza, para promover ambiente colaborativo nos locais de aprendizagem.

10. Agir e incentivar, pessoal e coletivamente, com autonomia, responsabilidade, flexibilidade, resiliência, a abertura a diferentes opiniões e concepções pedagógicas, tomando decisões com base em princípios éticos, democráticos, inclusivos, sustentáveis e solidários, para que o ambiente de aprendizagem possa refletir esses valores.

Fonte: Brasil (2020).

Desse modo, com o documento apresentado, pode-se perceber mudanças em relação ao foco da formação docente, no sentido de desqualificação das aprendizagens teóricas, e priorização do contexto prático da profissão. Visto também a falta de 
diálogo entre a proposta apresentada e pesquisadores da área da formação, deixando lacunas e fragmentações quanto a formação de professores/as.

\section{Considerações Finais}

Como foi possível perceber, a formação de professores/as no cenário brasileiro perpassou por vários formatos e sofreu diversas alterações desde seu surgimento, logo após a independência brasileira. As mudanças sociais, políticas e econômicas do país perpassaram também o cenário educativo, transformando a forma como compreendemos e vivemos a educação brasileira.

Não obstante, não podemos negar que esse processo foi centrado em uma elite: a educação era voltada para uma parte da população que compunha a aristocracia, e também amplamente firmada por valores morais-cristãos. O cenário político que inspirou essa mudança, também inspirou a criação das Escolas Normais, dos Institutos de Formação e dos Cursos de Magistério.

Quase dois séculos após o primeiro processo, a Base Nacional Comum Curricular surge para instituir a Base Nacional Comum para a Formação Continuada de Professores da Educação Básica (BNC-Formação Continuada), com foco em dez competências que urgem o desenvolvimento de competências profissionais. A análise do documento demonstra a mesma lacuna no diálogo entre a proposta e os pesquisadores da área de formação.

Nesses tempos incertos em que vivemos, ressaltamos a importância dessa proximidade, entre as legislações que entram em vigor e aqueles/as que tem se dedicado à pesquisa na área, de forma que possamos permitir que cada vez mais, educadores/as se reconheçam como sujeitos de sua própria formação e interrelacionem teoria e prática. Apenas assim, o contexto educativo estará alinhado com o contexto social, político e econômico, proporcionando uma educação dialógica e interativa entre todos que compõem esse processo.

Após as considerações finais deste estudo, pretende-se em pesquisas futuras possa-se ampliar os processos de investigação, aprofundando os contextos históricos explorados sobre a formação docente. Fazendo desse modo o complemento da complexidade da pesquisa iniciada neste trabalho, com aspectos relacionados as condições de trabalhos dos/as docentes, das relações entre os processos de ensino e aprendizagem, entre outros fatores que influenciam no densenvolvimento profissional docente.

\section{Referências}

Batista, D. E. A didática de Comênio: entre o método de ensino e a viva voz do Professor (2017). Pro.posições. 28(1), 256-276. https://www.scielo.br/scielo.php?script=sci_arttext\&pid=S0103-73072017000400256\&lng=pt\&tlng=pt

Borges, M. C. , Aquino, O. F. , \& Puentes, R. V. Formação de professores no brasil: história, políticas e perspectivas (2011). Revista HISTEDBR On-line, Campinas, (42), 94-112. https://periodicos.sbu.unicamp.br/ojs/index.php/histedbr/article/view/8639868

Bourdieu, P. (1989). O poder simbólico. Berthand Brasil/Difel.

Brancher, V. R. (2006). Helena Ferreira Teixeira: Entre saberes e representações. Dissertação de Mestrado. UFSM.

Brancher, V. R. , Baptista, E. H. , Maraschin, M. S. , \& Conceição, V. J. S. da. (2007). Formação do professor: algumas reflexões coletivas. Educere Et Educare-Revista de Educação. UNIOESTE. 2(4), 63-75. http://e-revista.unioeste.br/index.php/educereeteducare/article/viewFile/1655/1342

Brasil Império. Decreto No 7.247, DE 19 de Abril de 1879. https://www2.camara.leg.br/legin/fed/decret/1824-1899/decreto-7247-19-abril-1879-547933publicacaooriginal-62862-pe.html.

Brasil Império. Lei de 15 de outubro de 1827. http://www.planalto.gov.br/ccivil_03/leis/lim/LIM..-15-10-1827.htm\#: :text=LEI\%20DE\%201 $5 \% 20$ DE $\% 20$ OUTUBRO,lugares $\% 20$ mais $\% 20$ populosos\%20do\%20Imp\%C3\%A9rio.\&text=1\%C2\%BA\%20Em\%20todas\%20as\%20cidades,primeiras\%20le tras $\% 20$ que $\% 20$ forem $\% 20$ necess $\%$ C $3 \%$ A 1 rias.

Brasil. Decreto-Lei No 1.190, de 4 de Abril de 1939. Diário Oficial da União - Seção 1 - 6/4/1939, Página 7929 (Publicação Original). https://www2.camara.leg.br/legin/fed/declei/1930-1939/decreto-lei-1190-4-abril-1939-349241-publicacaooriginal-1-pe.html. 
Research, Society and Development, v. 10, n. 4, e59610414492, 2021

(CC BY 4.0) | ISSN 2525-3409 | DOI: http://dx.doi.org/10.33448/rsd-v10i4.14492

Brasil. Decreto-Lei № 8.530, de 2 DE janeiro de 1946. Diário Oficial da União - Seção 1 - 4/1/1946, Página 116 (Publicação Original). https://www2.camara.leg.br/legin/fed/declei/1940-1949/decreto-lei-8530-2-janeiro-1946-458443-publicacaooriginal-1-pe.html.

Brasil. Diretrizes Curriculares Nacionais para a Formação Continuada de Professores da Educação Básica e institui a Base Nacional Comum para a Formação Continuada de Professores da Educação Básica (BNC-Formação Continuada). resolução $\mathrm{CNE} / \mathrm{CP} \mathrm{N}^{\circ} 1$, de 27 de outubro de 2020 . https://www.in.gov.br/web/dou/-/resolucao-cne/cp-n-1-de-27-de-outubro-de-2020-285609724.

Brasil. Diretrizes Curriculares Nacionais para a Formação de Professores da Educação Básica, em nível superior, curso de licenciatura, de graduação plena. PARECER CNE/CP 9/2001. Despacho do Ministro em 17/1/2002, publicado no Diário Oficial da União de 18/1/2002, 1, 31. http://portal.mec.gov.br/cne/arquivos/pdf/009.pdf.

Brasil. Lei de diretrizes e bases da educação nacional. lei № 9.394, de 20 de dezembro de 1996. http://www.planalto.gov.br/ccivil_03/leis/19394.htm.

Cunha, M. I. Trabalho docente na universidade. (2005). In: Moreira, J. M. , Costa, E. M. B. (Org.). Pedagogia universitária: campo de conhecimento em construção. Cruz Alta, RS: EdUniCruzAlta. p. 99-115.

Deslandes, S. F. (1994). Pesquisa social: teoria, método e criatividade. Vozes.

Nóvoa, A. Formação de professores e profissão docente. (1995). In: (Org.) Antônio Nóvoa. Os professores e a sua formação. (2a ed.), Dom Quixote.

Oliveira, V. F. de. A formação de professores revisita os repertórios guardados na memória. (2000) In: Imagens de professor: significações do trabalho docente. (Org.) Valeska Fortes de Oliveira. Ed. UNIJUí.

Pádua, E. M. M. de. (2004). Metodologia da pesquisa: abordagem teórico-prática. (10a ed.), Papirus.

Pereira, A. S. , et. al. (2018). Metodologia da pesquisa científica, UFSM.

Saviani, D. Formação de professores: aspectos históricos e teóricos do problema no contexto brasileiro (2009). Revista Brasileira de Educação. 14(40). https://www.scielo.br/pdf/rbedu/v14n40/v14n40a12

SÁ-Silva, J. R. , Almeida, C. D. de , \& Guindani, J. F. (2009). Pesquisa documental: pistas teóricas e metodológicas. Revista Brasileira de História \& Ciências Sociais. I(I). https://periodicos.furg.br/rbhcs/article/view/10351 